\title{
The Holistic Focus of Social Work: The Interdependence of Global, National, and Local Perspectives in the Global Definition of Social Work
}

Stefan Borrmann

The question raised in this article is whether or not there is a global holistic focus on social work, even though social work is practiced mostly in a localized context and therefore in very different national, regional, and local cultural settings. The global definition of social work is a key document in this discussion regarding the connection between global and local interdependency because it claims to define global social work by definition on the one hand but on the other hand must find ways to integrate local social work practices. Interestingly, this connection can only be found implicitly in the definition. The article will focus on the underlying debate of cultural relativism and universalism and how a biopsychosocial theory of human needs can be one possible basis for the holistic focus of social work proposed in the definition itself.

Keywords: cultural relativism, indigenous knowledge, localization, universalism

The complex interplay between local and global contexts in social work education and practice is important for the social work profession. A key aspect is "whether the relationship between these two dimensions can be one of empowerment rather than one of oppression in the form of neo-colonialism conducted in and through social work" (Dominelli \& Hackett, 2011, p. 627). The key question of this article is whether a global holistic focus for social work can coexist with the localized context of most social work practice and the wide variation in national, regional, and local cultural settings. In the commentary notes of the "Global Definition of Social Work" (International Federation of Social Workers [IFSW], 2014), this contested relationship is stated directly: "The holistic focus of social work is universal, but the priorities of social work practice will vary from one country to the next, and from time to time depending on historical, cultural, political and 
socio-economic conditions." In this quote, the relationship between the holistic focus and the priorities of social work practice is explained. Social work practice varies depending on historical, political, and socioeconomic conditions. The universal aspect of social work is not further explained, however.

This article focuses on this lack of clarification and describes how the social work profession can find ways to explain its holistic focus on the basis of scientific reasoning and not just as an unreflected statement because "the relationship between the local and the global is a complex and contested one, with little consensus on either its meaning or interpretation in a practice context" (Dominelli \& Loakimidis, 2017, p. 265). In order to get a better understanding of this relationship, the first part of the article will reintroduce the global definition and some of its key points regarding the connection between global and local interdependency. The second part will outline the universalism versus cultural relativism debate because it provides the basis for the struggle to find a satisfying answer to the connection between the local and the global in social work. The third part will raise the question of whether the global definition has a stronger focus on universalism or on cultural relativism, which requires consideration of Western-centric versus indigenous social work. Finally, the holistic focus of social work and why it must be universal, as quoted at the beginning of this article, will be explained in more detail, with one possible answer provided as to the basis on which the holistic focus can be developed.

\title{
The Global Definition of Social Work
}

The IFSW (2014) has promulgated a global definition of social work:

\begin{abstract}
Social work is a practice-based profession and an academic discipline that promotes social change and development, social cohesion, and the empowerment and liberation of people. Principles of social justice, human rights, collective responsibility and respect for diversities are central to social work. Underpinned by theories of social work, social sciences, humanities and indigenous knowledge, social work engages people and structures to address life challenges and enhance wellbeing. The above definition may be amplified at national and/or regional levels.
\end{abstract}

Like almost every other definition, the global definition is the result of compromise. Therefore, there is no clear answer to the definition of the relationship between the local and the global. However, in the comments section there is an implication that one must at least take different system levels into question: "The social change mandate is based on the premise that social work intervention takes place when the current situation, be this at the level of the person, family, small group, community or society, is deemed to be in need of change and development" (IFSW 2014). The interdependence of people and their environment is discussed further: "Therefore, a major focus of social work is to advocate for the rights of 
people at all levels, and to facilitate outcomes where people take responsibility for each other's wellbeing, realize and respect the inter-dependence among people and between people and the environment."

Similarly,

Social work's legitimacy and mandate lie in its intervention at the points where people interact with their environment. The environment includes the various social systems that people are embedded in and the natural, geographic environment, which has a profound influence on the lives of people.

These three quotes can lead to at least three conclusions for further discussion:

1. There is a difference between informal and formal contextualization. Even though the local/global debate is not mentioned directly, it is inherent to the connection between individuals and their environment, at least when environment is defined on a systemic level.

2. This debate is about translating and adapting global standards to make their content appropriate and meaningful for the given circumstances (i.e., the local context). In this case, circumstances is meant to include the spatial level and therefore the connection between the local and the global.

3. As noted by Trygged (2010, pp. 644-655),

[a] crucial topic in the debate is to what extent social problems and social work can be said to be equivalent across the globe and whether practice knowledge can be generalized from one country to another. Both global and local knowledge at different levels is needed. Consensus is mainly about recognizing the need for local and indigenous knowledge in the balancing act that is social work.

This last conclusion, specifically "the balancing act," refers to a debate that is much older than the current global definition: universalism versus cultural relativism.

\section{Connecting the Local to the Global: The Universalism versus Cultural Relativism Debate}

Lynn Healy (2007) stated that there is an interdependence between progressing globalization and the relevance of the universalism-relativism debate:

The relevance of the universalism-relativism debate to social work has grown with the increased globalization of the profession and its practice context; it is applicable not only to cross-national practice and cross-national efforts to define the profession, but increasingly to social work within countries, as more and more countries have become multicultural. (p. 11) 
It therefore becomes clear that there will be increased discussions in social work about this topic. A brief literature review shows that, for example, in the journal International Social Work, the number of articles focusing on localization aspects has been growing for the last few decades. From 1990 to 1999 there were 11 articles with the search term localization. The amount of hits almost doubled in the time span from 2000 to 2009, with 21 articles, and more than doubled again, with 54 articles found, from 2010 to 2019. The connection to the globalization debate seems to be evident from the number of articles about globalization, which grew in the same time span from 22 (1990-1999) to 178 (2000-2009) and then to 213 (2010-2019). Even more indicative is the growing number of articles that feature both terms, localization and globalization. They increased from none between 1990 and 1999 to 13 from 2000 to 2009 and to 26 between 2010 and 2019. This shows that if globalization is proceeding, then the debate about localization versus globalization in social work will proceed as well.

What is this debate about? It is closely connected to the human rights debate. The universalist position states that every human being has the same rights and that culture may influence the direction of the discussion but is irrelevant to the validity of moral rights and rules. The opposite view - the cultural relativism standpoint-argues that culture is the sole source of validity of moral rights and rules and that there are no common standards. And of course, there are variations on the positions. Healy (2007, p, 12) visualized these standpoints as shown in figure 1.

Every social worker is faced with the question of how to position herself or himself in this debate. On what basis should they decide? If social workers encounter cultures "with values that conflict with their own," Healy (2007, p. 13), summarized with reference to Donaldson (1996), asked the "practical question: when is different just different and when is different wrong?" It becomes even more difficult when social work acknowledges that all cultures, regardless of their (geographical) location, are dynamic and can be defined as "constantly contested and negotiated social practices whose meanings are influenced by the power and status of their interpreters and participants" (Healy, 2007, p. 24).

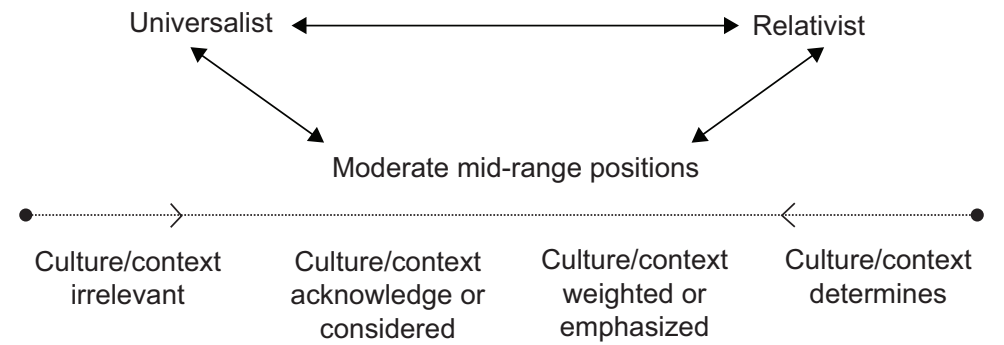

Figure 1 The universalist/cultural relativist continuum for ethical decision-making (Healy 2007, p. 12) 


\section{Localization or Globalization: An Analysis of the Global Definition}

In practice, education, or research, social work must fail when it is Western centered and ethnocentric. Hokenstad (2012, pp. 172-173) referred to this criticism when he raised the question of whether or not current international social work education/practice "perpetuates cultural and intellectual imperialism and discourages development or valuing of indigenous models by promotion of dominant western ideas and practices." There is an ongoing discussion about the integration (or reintegration) of indigenous knowledge in the social work profession, especially about knowledge developed in Asia or Africa (i.e., Spitzer, Twikirize, \& Wairire, 2014). However, social work should be careful not to repeat the error of idealizing knowledge just because it was developed in a specific region, by a specific group of people, or from a specific cultural background. The global definition of social work is one example of this unbalanced leaning toward the cultural relativist view. Examples include the following:

1. Social work could promote social cohesion in a homogeneous society by stabilizing societal structures that are unjust. This might be contrary to the liberation of people and the empowerment of marginalized groups (i.e., refugees from another cultural background) and might thereby challenge social cohesion. We currently see this in many European countries with the rise of right wing populist movements (Borrmann, Anan, Schuster-Craig, \& Frost., 2017).

2. The bases for social work according to the global definition are theories of social work as well as indigenous knowledge. But the terms theories and knowledge imply a certain logic of knowledge production. What if the logic behind these is incompatible?

3. Human rights are individual rights. Collective responsibility refers to groups, communities, or societies. What if holding up culturally justified practices, such as female genital mutilation, to stabilize a community (and thereby promote social cohesion) can be seen as human rights violations on the individual level?

The last two examples have an especially strong tie to the previous discussion. Being a cross-culturally competent social worker means that one should be able to see the contradictions in the definition and contextualize them in a productive way. This means that international social work does not have to have an answer for these questions. In many cases, there may be no answer.

In the global definition, there are several elements that reflect the character of compromise and the willingness to acknowledge the tension between Westerncentric social work and social work of the Global South, including indigenous social work. One of these elements is the integration of indigenous knowledge as the knowledge base of social work, which was part of the effort to acknowledge 
the historic responsibility of social work. With regard to knowledge, the commentary section for the global definition states that:

Part of the legacy of colonialism is that Western theories and knowledges have been exclusively valorised, and indigenous knowledges have been devalued, discounted, and hegemonised by Western theories and knowledge. The proposed definition attempts to halt and reverse that process by acknowledging that Indigenous peoples in each region, country or area carry their own values, ways of knowing, ways of transmitting their knowledges, and have made invaluable contributions to science. Social work seeks to redress historic Western scientific colonialism and hegemony by listening to and learning from Indigenous peoples around the world. In this way social work knowledges will be co-created and informed by Indigenous peoples, and more appropriately practiced not only in local environments but also internationally. (IFSW, 2014)

Even though I share the belief that the shameful past of the profession in times of historical colonization and its lasting impact must be acknowledged, I do not agree with the part of the definition that mixes scientific theories and indigenous knowledge in one sentence. The definition and the comments section state that indigenous people have made invaluable contributions to science. To be clear, indigenous people have made invaluable contributions to social work practices and methods. But whether or not this can be categorized as a science is at least questionable. And this argument is not posed from an epistemological colonial perspective, but based on the foundation of scientific reasoning. Specifically, scientific theories have to be self-reflexive by definition and indigenous knowledge does not. Scientific theories-at least in social science and humanities-must take into account that the societal contexts in which they are developed are continually changing and must be considered. Even though this assumption must be questioned, indigenous knowledge-at least in many publications (i.e., Straub, 2016) — tends to be seen as culturally static. The static nature of indigenous knowledge is seen as a value on its own (Straub, 2016).

An interesting question remains: Does social work, with reference to indigenous knowledge, develop concepts that take into account the everchanging culture in which it is developed? One framework for doing so is provided by Tracie Mafile'o and Halaevalu Ofahengaue Vakalahi (2018) in their article "Indigenous Social Work across Borders: Expanding Social Work in the South Pacific." In this article the authors argued that social justice, locally led development, and cultural preservation will be better realized with the expansion of Pacific social work across borders. They acknowledged the tremendous importance of locally and culturally embedded social work, but clearly stated that social work in that sense must expand and integrate experiences that are made in other countries 
and cultures (in this example from expatriates). In order to do this, they compared and developed frameworks on how to integrate the knowledge:

Current understandings of indigenization emphasize social work that is interpreted from a local frame of reference and is locally and culturally relevant (Gray and Coates, 2010). Pacific indigenous social work, however, while culturally specific, has developed across nation-state borders reflecting the diaspora of Pacific peoples outside of Pacific homelands. (p. 537)

Mafile'o and Vakalahi have made it very clear that they see great value in focusing on indigenous knowledge from the Pacific for social work:

Overall, indigenous Pacific frameworks and models possess some common characteristics. First, Pacific approaches stem from within an ethnicspecific Pacific worldview, rather than being primarily an adaptation of Western social work to fit a local cultural context (Gray and Coates, 2010). That is, the theory and knowledge for practice begins within the specific Pacific worldview, which then incorporates aspects from the non-Pacific context. Second, Pacific indigenous languages or metaphors typically comprise the concepts within the framework or model. Third, Pacific ethnicspecific approaches derive from cultures which are primarily oral and have an emphasis on the spiritual; thus, their richness may not necessarily be reflected in written forms, but in practice and in the playing out of relationships. Fourth, the primary starting point and focus is on Pacific ethnic groups working with their own people, rather than on how social workers might work cross-culturally with Pacific peoples. Finally, Pacific approaches have been developed by and written about mostly in reference to Pacific peoples in the diaspora, rather than "homelands"-a reflection of the development of the profession in the diaspora compared to the homelands and the resources available (human, financial and professional) for such developments to take place. (p. 543)

But - and this is a very important addition - they clearly see that an unreflected approach that idealizes indigenous knowledge is not sufficient in societies that are no longer self-centered but are also part of the globalized world. Therefore, their suggestion is to look for a third space where the extreme positions of universalism or relativism are avoided:

The notion of Pacific social work reflects issues negotiated broadly in social work, such as the negotiation of cultural universals and cultural specifics, and the tensions between globalization and indigenization. The applicability of a universal set of standards for social work or social work education globally has been questioned (Gray and Fook, 2004; Midgley, 2008). Yet improving the well-being of transnational, diasporic Pacific peoples is 
encompassed by the Global Agenda for Social Work and Social Development, which includes promoting social and economic equalities, the dignity and worth of peoples, environmental sustainability and recognition of the importance of human relationships (The Global Agenda for Social Work and Social Development Commitment to Action, 2012). Issues with cultural relativism, on the other hand, have also been raised, particularly from a human rights perspective (Reichart, 2007). Pacific social work will necessarily involve a 'third space' (Reichart, 2007) or ethical pluralism (Hugman, 2013) where the extreme positions of universalism or relativism are avoided. (p. 547)

This raises another question: Is the global definition of social work open enough to provide such a "third space" while describing social work on a global level? This is where the connection between the holistic focus as a universal basis of social work and the localization of social work practices becomes important. A third space must be able to integrate both positions. Therefore, further explanation of the universal base of social work is needed.

\section{The Universal Basis of Social Work}

In reference to social work education with an international focus, Hokenstad (2012) stated that "models and opportunities for International Social Work Education include 'infusion' through regular courses; specialist options and degree-bearing programs; and student and faculty exchange." And although these are all suitable options, it is the understanding of this article that one must focus on the underlying personal prerequisite to internationalize social work education - and in this case practice - successfully. The most important prerequisite is that social workers, social work students, and faculty members have a deep understanding of cross-cultural competencies. This understanding starts with the acknowledgment that personal and cultural beliefs have a tremendous impact on how we teach, how we learn, and how we practice social work. It continues with the realization that one's status in society - power — must be seen as a major factor in the debate about universalism and cultural relativism. An intersectional analysis of one's role in society is only a starting point in the deconstruction of one's own belief system. Therefore, the goal of international social work education is to denationalize the social work curricula and enable social workers to be highly reflective persons (Borrmann, in press). The goal is to develop "global mindedness" (Anand \& Das, 2019) within the social work profession. But it also means that the social work profession cannot deny the most basic underlying understanding of what social work should be and should accomplish on a local, national, and global level. If social work is about enhancing the well-being of people, as mentioned in the global definition, it must accept some universalistic understandings.

The universal basis of social work lies in the fact that social work engages people in their relationship to structures on different spatial and cultural levels. And if 
it is self-evident that these structures are highly formed and influenced "from one country to the next, and from time to time depending on historical, cultural, political and socio-economic conditions" (IFSW, 2014), then one must ask if there is a constant not dependent on these conditions and therefore a constant on which the universal focus of social work can rely. The suggestion is that human needs, defined in a biopsychosocial sense, can be seen as the universal basis on which social work agrees. All human beings have needs they wish to satisfy. As stated by the United Nations (1987),

Human Rights could be generally defined as those rights which are inherent in our nature and without which we cannot live as human beings. Human Rights and fundamental freedoms allow us to fully develop and use our human qualities, our intelligence, our talents and our conscience and to satisfy our spiritual and other needs. They are based on mankind's increasing demand for a life in which the inherent dignity and worth of each human being will receive respect and protection. (p. 4)

This type of biopsychosocial theory of human needs is based in moral realism (Borrmann, 2009). The basic idea of the ethical theory of moral realism is that values are grounded in the nature of humans. People value positively anything they need for their well-being. Therefore, human needs and wants are the roots of values, and the function of norms is to protect these needs. "The good" and "the right" are sometimes objective (in terms of biological needs) and at other times subjective (in terms of psychological and social needs), but they are always relative to people and their environment (Bunge, 1989). Mario Bunge's theory of moral realism $(1967,1989,1996,1998)$ was applied to social work by Swiss scholar Werner Obrecht $(2001,2005)$. There are three types of interdependent human needs: biological or physiological, biopsychological, and biopsychosocial. To maintain a state of well-being, all three of these needs must be met. However, there is a hierarchy of needs (Maslow, 1943; Obrecht, 2005), with biological or survival needs (i.e., the need for food and shelter) higher on the hierarchy than social needs (i.e., the need for social support). Because needs are conditions of the organism, they are part of the human being's intrinsic makeup and as such are universal. All human beings have the same needs and must obtain the resources necessary to fulfill their needs even though the ways in which different groups of human beings go about trying to meet their needs differ from country to country, social group to social group, or culture to culture.

If human beings cannot fulfill their needs, due to personal, structural, societal, or any other reason, social work should intervene. Rights-human, social, and cultural - are there to provide a structure for need fulfillment. Well-being can be defined as the absence of the urge to fulfill needs. And with all the difficulties that are accessory to such concepts of human beings and social work (because, for example, there can be conflicting and competing needs of different kinds of persons), one thing is clear. In the defined concept of human needs lies the most basic 
universalistic understanding possible: all human beings are equal! And this might be the underlying hypothesis in the commentary section of the global definition, which says, "The holistic focus of social work is universal" (IFSW, 2014).

\section{Conclusion}

This article asks whether or not the global definition provides an answer about the role and relationship of the local and the global in social work. The answer is, unsurprisingly, no. The definition is ambivalent in positioning itself within the underlying debate about the relation between universalism and cultural relativism. For social work, this debate is highly visible in discussions about the role of indigenous knowledge and indigenous social work. A solution can be found only by developing a third space for debate about the local and the global. This must be an undisputed acknowledgment of the worth and dignity of every human being derived from a rights-based approach. But this also means accepting that social work is deeply rooted in the relationship of individuals in their environment and therefore must be contextual and local. The only way to find common ground in this discussion is to accept and integrate the belief that every culture is not static but always changing. In order to find this common ground, we need social workers who are self-reflective and globally minded.

\section{References}

Anand, C .J., \& Das, C. (2019) Global mindedness in international social work practice. London, UK: Macmillan Education.

Borrmann, S. (in press). Personal and structural prerequisites for international social work education. In R. Rosskopf \& B. Heilmann (Ed.), Handbook for international social work with refugees. Leverkusen, Germany: Budrich Publishers.

Borrmann, S. (2009). Ethical dilemmas in practice. In M. Gray \& S. A. Webb (Ed.), Value perspectives in social work (pp. 51-59). London, UK: Palgrave Macmillan.

Borrmann, S., Anan, J. C., Schuster-Craig, J., \& Frost, C. (2017). Integration or inclusion? Defining terms in the context of refugee resettlement and rightwing populism, Social Dialogue, 17(9), 15-17.

Bunge, M. (1967). Scientific research II: The search for truth. New York, NY: Springer.

Bunge, M. (1989). Ethics: The good and the right. Dordrecht, Netherlands: Kluwer.

Bunge, M. (1996). Finding philosophy in social science. New Haven, CT: Richard Henderson.

Bunge, M. (1998) Philosophy of science. Vol. 2: From explanation to justification. London, UK: Transaction Publishers.

Dominelli, L., \& Hackett, S. (2011). Editorial: Interplays between local and global contexts in social work. International Social Work, 54, 627-628. doi:10.1177/0020872811418284 
Dominelli, L., \& Loakimidis, V. (2017). The local-global nexus in social work education and practice. International Social Work, 60, 265-270. doi:10.1177/0020872817694111

Healy, L. M. (2007). Universalism and cultural relativism in social work ethics. International Social Work, 50, 11-26. doi:10.1177/0020872807071479

Hokenstad, T. (2012). Social work education: The international dimension. In K. Lyons, T. Hokenstad, M. Pawar, N. Huegler, \& N. Hall (Ed.), SAGE handbook of international social work (pp. 163-178). Los Angeles, CA: SAGE.

International Federation of Social Workers. (2014). Global definition of social work. Retrieved from https://www.ifsw.org/what-is-social-work/ global-definition-of-social-work

Mafile'o, T., and Vakalahi, H. F. O. (2018). Indigenous social work across borders: Expanding social work in the South Pacific. International Social Work, 61, 537-552. doi:10.1177/0020872816641750

Maslow, A. H. (1943). A theory of human motivation. Psychological Review, 50, 370-396.

Obrecht, W. (2001). Das Systemtheoretische Paradigma der Disziplin und der Profession der Sozialen Arbeit: Eine transdisziplinäre Antwort auf das Problem der Fragmentierung des professionellen Wissens und die unvollständige Professionalisierung der Sozialen Arbeit [The systemic paradigm of social work: A transdisciplinary answer to the problem of the fragmentation of professional knowledge and the incomplete professionalization of social work]. Zürich, Switzerland: Hochschule für Soziale Arbeit Zürich.

Obrecht, W. (2005). Umrisse einer biopsychologischen Theorie menschlicher Bedürfnisse: Geschichte, Probleme, Struktur, Funktion .[A biopsychosocial theory of human needs: History, problems, structure, function]. Vienna, Austria: Wirtschaftsuniversität Wien.

Spitzer, H., Twikirize, J. M., \& Wairire, G. G. (2014). Social work in East Africa: Towards social development, poverty reduction and gender equality. Kampala, Uganda: Fountain Publishers.

Straub, U. (2016), All my relations - indigene Ansätze und Relationalität in der Sozialen Arbeit [Indigenoius knowledge and relational knowledge]. In F. Früchtel \& M. Strassner (Ed.), Relationale Sozialarbeit-versammelnde, vernetzende und kooperative Hilfeformen (pp. 54-74). Weinheim, Germany: Beltz-Juventa.

Trygged, S. (2010). Balancing the global and the local: Some normative reflections on international social work. International Social Work, 53, 644-655. doi:10.1177/0020872810371204

United Nations. (1987). Human rights. Questions and answers. New York, NY: Author. 